\title{
Community health risk assessment after a fire with asbestos containing fallout
}

\author{
S Bridgman
}

\begin{abstract}
Background-A factory fire in Tranmere, Merseyside, England, deposited asbestos containing fallout in an urban area. There was considerable community anxiety for months after the incident. Therefore an assessment of the long term health risks of this acute environmental incident were requested by the local health authority. Methods-The facts of the incident were gathered and appraised from unpublished and press reports, involved personnel, and further analysis of material collected at the time of the incident. The literature on the long term health risks of asbestos was reviewed, and combined with evidence on asbestos exposure to estimate community health risk.

Results-Risk was almost entirely from exposure to fire fallout of chrysotile in asbestos bitumen paper covering the factory roof. Amosite was only detected in a few samples and in trace amounts. The number of people who lived in the area of fallout was 16000 to 48000 . From a non-threshold model with assumptions likely to overestimate risk, the lung cancer risk is estimated to be undetectably small. Risk of mesothelioma from chrysotile exposure, and risks of lung cancer and mesothelioma from amosite exposure were based on observational studies and were estimated to be even lower than that of lung cancer risk from chrysotile exposure. Academically, there are assumptions that while reasonable cannot be proven, for example, the validity of extrapolating observed risk from much higher exposures to lower exposures, estimates of individual exposure, and that there is no threshold for asbestos to cause cancer. Conclusions-The author is unaware of a similar study on long term health risks in a community exposed to asbestos in a fire. It is concluded that, using methods that do not underestimate risk, risk is undetectably small. Practical lessons from this methodology and approach to health risk assessment are discussed.

(F Epidemiol Community Health 2001;55:921-927)
\end{abstract}

Asbestos is a generic term for six natural silicate minerals. They are divided into two subgroups, serpentines and amphiboles. Chrysotile or white asbestos is the only serpentine. The others, including blue asbestos (crocidolite) and brown asbestos (amosite), are amphiboles. When crushed or processed the mineral seperates into flexible fibres. These have been spun into yarn, woven into fabric, braided into rope and added to materials as diverse as cement, asphalt, plaster, and cotton. The ancient Egyptians used asbestos cremation cloths and mats, and it was used in Finnish pottery in $2500 \mathrm{BC}{ }^{1}$ In the 20 th century millions of tons of asbestos have been used worldwide in over 3000 products. $^{2-4}$

Health risks from asbestos have engendered fear, panic, ${ }^{5}$ and a large amount of public anxiety. ${ }^{6}$ Such fear is not surprising given knowledge of the untoward health experiences of some communities exposed to asbestos and current industrial health promotion messages such as Be aware of asbestos - the hidden killer and Asbestos dust kills. ${ }^{78}$ Browne classifies asbestos related disorders into non-malignant and malignant. ${ }^{9}$ Non-malignant disorders include asbestosis (diffuse interstitial pulmonary fibrosis), hyaline plaques of the parietal pleura, diffuse thickening of the pulmonary pleura, benign pleural effusions and skin corns. The principal malignant disorders consist of lung cancer and malignant mesothelioma of the pleura and peritoneum. Different fibres may have different health effects.

On 22 September 1994 a major fire occurred at a disused leather factory at Tranmere, Merseyside, England. Fallout from the fire consisted of both large paper-like material and fine particles. A concerned member of the public contacted the local environmental health department. It was later reported that the fallout contained both white (chrysotile) and brown (amosite) asbestos. A clean up operation was carried out over the next two days. The public were informed by the local authority and health authority that the dangers of such an incident should be minimal. Despite this advice, publicity and controversy over health risks continued. Therefore Wirral Health Authority commissioned this study of the health consequences and lessons learnt from the incident, some months after the acute part of the incident had been dealt with. Lessons learnt, acute health consequences, and details of the incident are reported elsewhere. ${ }^{10-12}$ To assess acute health effects, studies were carried out of accident and emergency attenders within two days of the fire, hospital admissions within 28 days of the fire, compensation claims for symptoms and diseases within nine months of the fire, and mapping of calls for assistance to the council and compensation claims. While many symptoms and diseases in several hundred people seeking compensation were recorded, there was no hard evidence to suggest that these acute health effects were directly attributable to the fire. 
The objective of this paper is to report on the methods and results of an assessment of the long term health risks of this incident.

\section{Methods}

Empirical data on likely level of exposure was combined with evidence of health risk from the literature to assess the likely health risks in this incident.

EMPIRICAL EVIDENCE ON ENVIROMENTAL CONTAMINATION WITH ASBESTOS

Information about the incident was sought from agencies involved in the fire, in particular the local authority, fire brigade, Police, Wirral Trades Union Council, Health and Safety Executive (HSE), Wirral Borough Council, Liverpool Public Analyst, and the factory owners. Press reports about this incident were obtained from the public library.

An estimate of the surface area of the factory affected by the fire was calculated from the fire brigade's fire report and an external consultant's report. As the factory roof was corrugated, its surface area was calculated by direct measurement from its flat paper equivalent.

Specimens of fire fallout were collected by environmental health officers. Samples were analysed at the HSE North West Field Consultant Group Science Section laboratory in Manchester. This laboratory was accredited for asbestos measurement by the National Measurement Accreditation Scheme (NAMAS). The sample was subject to a systematic approach of isolation of different types of asbestos fibre by polarised light microscopy for bulk analysis. ${ }^{13}$

When the author asked for these samples to be quantitatively analysed, they had been disposed off by the HSE as they generally only keep samples for a year. Fortunately some samples had been retained by Wirral Borough Council. Therefore seven samples from recorded locations, three samples from unrecorded locations, and a sample of unburnt felt, were analysed by the NAMAS accredited Health and Safety Executive laboratory in Sheffield. Analysis was by both polarised light microscopy and $x$ ray diffraction.

Within a week of the fire, a consultancy firm (Parkman Environment) performed a study that aimed to identify possible sources of asbestos within and in the immediate vicinity of the fire damaged buildings. All materials visually assessed as likely to contain asbestos were sampled, including fibrous and flaky material, lagging, grey cement-like sheeting, and chipped slabs. Samples were also taken from charred debris lying on the floor, dust and ashes deposited on window sills, and the demolition material at the front of the building. A total of 22 samples were taken and analysed for asbestos content by Scientific Analysis Laboratories Ltd by their standard operating procedures (details of this are unavailable).

The demolition of the factory took place between 30 November and 6 December. Demolition work involved cutting and moving metal debris, and loading it onto two wagons. During demolition 12 air samples were taken by Brian Milligan Associates to a schedule devised by SAT consultants in accordance with Health and Safety Executive recommendations based upon the European reference method, using cowled sampling heads and $25 \mathrm{~mm}, 1.2$ $\mu \mathrm{m}$ pore size, gridded, membrane filters. ${ }^{14} 15$ Fibre counting was performed by phase contrast optical microscopy with at least $\times 500$ magnification; a calibrated Walton and Beckett eyepiece graticule, and a HSE/NPL Mark 2 phase contrast test slide. All "fibres" as defined in HSE advice were counted. ${ }^{14}$ As this technique does not allow for differentiation between asbestos and non-asbestos fibres it can only indicate the total fibre content of the air sampled.

No other air samples to measure air fibre levels were taken in this incident.

Two fire tunics, and a polyester/cotton raincoat worn by firemen were sent to the Liverpool public analyst. He extracted dust by vacuum air section onto filters, which were examined by light microscopy. ${ }^{14}$ The uniform of a policeman who had been on duty most of the night of the fire was sent for optical microscopy analysis for asbestos contamination by the Occupational Health Laboratory at Cleckheaton.

Meteorological data was obtained from the local station at Bidston Observatory, which is approximately two miles from the factory.

Postcodes of members of the public who telephoned the environmental health department were plotted on a map of the Wirral using a commercial geographical mapping system. Polygons were drawn by eye around areas of greatest to least density of calls. Populations in the polygons were estimated from the 1991 Census Enumeration District Data held on the programme ARC/INFO (ESRI UK).

EVIDENCE OF RISK FROM THE LITERATURE

A literature review was undertaken by searching Medline with the terms, "asbestos", "lung cancer", and "mesothelioma". Identified papers were hand searched for further references. In addition the incident was discussed with United Kingdom experts in order to locate further relevant papers.

\section{Results}

EMPIRICAL EVIDENCE OF ASBESTOS IN FALLOUT In the six samples analysed early after the incident by the HSE, all had substantial amounts of chrysotile, one had a trace amount of amosite and two unquantified amounts of amosite (table 1). Polarised light microscopy on its own is rarely able to definitively distinguish amphibole asbestos types, as the only good discriminator between types is refractive index which requires a reasonable sample, rather than just a trace (Hoskins, personal communication). Thus it would be correct to describe these samples as containing a trace of amphibole asbestos, probably amosite (Hoskins, personal communication, Tylee, personal communication).

Of the second batch of samples analysed, most contained substantial amounts of chrysotile (around $50 \%$, table 1). None of this batch 
Table 1 Summary of analytical results from asbestiform samples deposited in the environment and collected by environmental health officers, and of an unburned sample of asbestos-bitumen felt

\begin{tabular}{|c|c|c|c|c|c|c|c|}
\hline No. & Sample site & Date taken & Date analysed & Chrysotile & Amosite & Fosterite & Chrysotile \\
\hline 43 & 12 Christchurch Road, Oxton & $22 / 9 / 94$ & $22 / 9 / 94$ & Yes-S & Yes-T & & \\
\hline 44 & Rectory Close & $22 / 9 / 94$ & $12 / 10 / 94$ & Yes & No & & \\
\hline 45 & Slatey Road & $22 / 9 / 94$ & $12 / 10 / 94$ & Yes & Yes & & \\
\hline 46 & Brattan Road & $22 / 9 / 94$ & $12 / 10 / 94$ & Yes & No & & \\
\hline 47 & Victoria Road & $22 / 9 / 94$ & $13 / 10 / 94$ & Yes & No & & \\
\hline 48 & Larch/Borough Rd & $22 / 9 / 94$ & $13 / 10 / 94$ & Yes & Yes & & \\
\hline 126 & Unburnt Paper & & $22 / 12 / 95$ & Yes & No & No & $57+12 \%$ \\
\hline 127 & Chestnut Grove & $22 / 9 / 94$ & $22 / 12 / 95$ & No & No & No & \\
\hline 128 & Olive Mount & $22 / 9 / 94$ & $22 / 12 / 95$ & Yes & No & Minor & $48+10 \%$ \\
\hline 129 & New Chester Road & $22 / 9 / 94$ & $22 / 12 / 95$ & No & No & No & \\
\hline 130 & New Chester Road & $22 / 9 / 94$ & $22 / 12 / 95$ & Yes-S & No & Yes & \\
\hline 131 & Upton Road & $22 / 9 / 94$ & $22 / 12 / 95$ & Yes-S & No & Minor & \\
\hline 132 & Redmond Street & $22 / 9 / 94$ & $22 / 12 / 95$ & Yes & No & Yes & $<3 \%$ \\
\hline 133 & Convent Close & $22 / 9 / 94$ & $22 / 12 / 95$ & No & No & No & \\
\hline 134 & Not stated & $22 / 9 / 94$ & $22 / 12 / 95$ & Yes & No & Minor & $61+12 \%$ \\
\hline 135 & Not stated & $22 / 9 / 94$ & $22 / 12 / 95$ & Yes & No & Minor & $57+12 \%$ \\
\hline 136 & Not stated & $22 / 9 / 94$ & $22 / 12 / 95$ & Yes & No & Minor & $51+10 \%$ \\
\hline
\end{tabular}

(Source: Health and Safety Executive). S = substantial (1-50\%), T = Trace (less than $1 \%$ ), or quantification not undertaken. Samples 43-48 were analysed by polarised light microscopy in 1994. Samples 126 to 136 were analysed by both polarised light microscopy and $x$ ray diffraction in 1995. Glass fibre was identified in samples 127 and 129. Sample 133 was a charred sample in which asbestos could have been present before burning. Fosterite is a reaction product of chrysotile asbestos when heated in excess of $500^{\circ} \mathrm{C}$. Samples 130 and 131 consisted of a loose collection of material too small to quantify by $x$ ray diffraction.

of samples was found to contain amosite. Analysis of a specimen of unburnt asbestos roofing paper also showed about $50 \%$ chrysotile content.

On study of samples from the factory prior to demolition, four were confirmed as containing chrysotile (table 2). A further two samples were reported to contain amosite-like fibres, which were probably not asbestos, but which would have required electron microscopy for definitive identification.

During demolition of the factory, the concentration of fibres in all samples was lower than 7 fibres per 100 graticule areas, and this may be considered the lowest reliably detectable level above background..$^{15}$ It is concluded that during demolition of the fire damaged area air asbestos fibre concentrations did not exceed

Table 2 Details of the results of the six positive or probably positive samples out of 22 samples taken by Parkman Environment after the fire at the Tranmere Tannery site

\begin{tabular}{lllll}
\hline $\begin{array}{l}\text { Sample } \\
\text { number }\end{array}$ & Asbestos type & Description of sSample & \% Asbestos & Risk \\
\hline 1 & Chrysotile & Asbestos cement wall sheeting & 15 & Low \\
9 & Chrysotile & Asbestos cement pipe & 13 & Low \\
10 & Chrysotile & Asbestos cement sheeting & 13 & NS \\
15 & Chrysotile & Woven tape from fuse & 100 & Very low \\
$2^{\star}$ & Amosite like & Pink paint flake & 16 & Low \\
$3^{\star}$ & Amosite like & Green flake & 15 & Low \\
\hline
\end{tabular}

(Source: Parkman Environment 1994).

${ }^{\star}$ In samples 2 and 3 probably non-asbestos fibres were identified, but further analysis would have been required for confirmation. NS = not stated. normal background levels (table 3). As there was no evidence of increased asbestos levels even when the material was being disturbed during removal, it is assumed that any asbestos that might have been left on site did not result in increased air asbestos concentrations.

An insignificant number of chrysotile fibres were identified in the weave of the outer fabric of the firemen's tunic (table 4). No asbestos fibres were found on the policeman's uniform or the polyester/cotton raincoat of the firemen.

QUANTITY OF ASBESTOS DEPOSITED IN THE ENVIRONMENT AND EXPOSURE ESTIMATES In a real-life incident like the Wirral fire, which potentially involves thousands of people, it is clearly impossible to know the asbestos exposure levels of each person. It is, however, possible to estimate maximum likely exposure based on the facts of the incident.

Table 4 Number and concentration of asbestos fibres found on two firemen's tunics and a control garment

\begin{tabular}{llll}
\hline & Tunic 1 & Tunic 2 & $\begin{array}{l}\text { Control } \\
\text { garment }\end{array}$ \\
\hline Rear of tunic, site a & 3 & 4 & 0 \\
Rear of tunic, site b & 3 & 3 & 0 \\
Front of tunic & 2 & 1 & 0 \\
Average fibres/square foot & 2.7 & 2.7 & 0
\end{tabular}

(Source: Mr M McDonnell, Liverpool Public Analyst).

Table 3 Summary of air sampling work during demolition of the British Leather Factory, Tranmere. In the analyst's opinion most fibres counted on 6 December, were consistent with organic fibres (no comment was made about fibres seen on 30 November)

\begin{tabular}{|c|c|c|c|c|c|c|c|c|}
\hline $\begin{array}{l}\text { Sample } \\
\text { ref }\end{array}$ & $\begin{array}{l}\text { Date of } \\
\text { sampling }\end{array}$ & $\begin{array}{l}\text { Type of } \\
\text { sample }\end{array}$ & Location of sampler & $\begin{array}{l}\text { Time of } \\
\text { sampling }\end{array}$ & $\begin{array}{l}\text { Fibres } \\
\text { counted }\end{array}$ & $\begin{array}{l}\text { Results } \\
\text { fibres } / m l\end{array}$ & $\begin{array}{l}\text { Flow rate } \\
1 / \text { min }\end{array}$ & $\begin{array}{l}\text { Graticule areas } \\
\text { counted/filter }\end{array}$ \\
\hline 1347 & 30 Nov 94 & Static & East end of work areas on wall & 1h $57 \mathrm{~min}$ & 5.0 & $<0.01$ & 2 & 300 \\
\hline 1348 & 30 Nov 94 & Static & South end of work area on wall beneath fire damaged roof & 1h $25 \mathrm{~min}$ & 6.5 & $<0.01$ & 2 & 300 \\
\hline 1349 & 30 Nov 94 & Static & West end of work area on wall & 1h $23 \mathrm{~min}$ & 6.5 & $<0.01$ & 2 & 300 \\
\hline 1350 & 30 Nov 94 & Static & North end of work area on wall & I h $20 \mathrm{~min}$ & 4.0 & $<0.01$ & 2 & 300 \\
\hline 1351 & 30 Nov 94 & Personal & Inside cab of excavator & $1 \mathrm{~h} 01 \mathrm{~min}$ & 4.5 & $<0.04$ & 1 & 200 \\
\hline 1356 & 06 Dec 94 & Personal & Inside excavator cab & Oh $47 \mathrm{~min}$ & 1.0 & $<0.12$ & 1 & 100 \\
\hline 1362 & 06 Dec 94 & Personal & Inside excavator $\mathrm{cab}$ & $4 \mathrm{~h}$ & 5.0 & $<0.02$ & 1 & 100 \\
\hline 1361 & 06 Dec 94 & Personal & On person by stairwell & $4 \mathrm{~h} 30 \mathrm{~min}$ & 3.0 & $<0.02$ & 1 & 100 \\
\hline 1357 & 06 Dec 94 & Static & East end of work area on wall & $2 \mathrm{~h}$ & 6.0 & $<0.01$ & 2 & 200 \\
\hline 1358 & 06 Dec 94 & Static & $\begin{array}{l}\text { South end of work area on wall where contaminated sheets } \\
\text { were stored }\end{array}$ & $2 \mathrm{~h}$ & 3.5 & $<0.01$ & 2 & 200 \\
\hline 1359 & 06 Dec 94 & Static & West end of work area on wall & $1 \mathrm{~h} 14 \mathrm{~min}$ & 2.5 & $<0.01$ & 2 & 200 \\
\hline 1360 & 06 Dec 94 & Static & North end of work area on wall adjacent to New Chester Road & $2 \mathrm{~h} 15 \mathrm{~min}$ & 3.0 & $<0.01$ & 2 & 200 \\
\hline
\end{tabular}

For samples 1356, 1361 and 1362, work involved cutting and moving metal debris and loading it on to two wagons for subsequent disposal, with disturbance of asbestos contaminated debris. For samples $1357-1360$ the contractors disturbed contaminated debris and the air in the vicinity of the sample. For samples $1347-51$, the air was being actively disturbed by the contractors. 


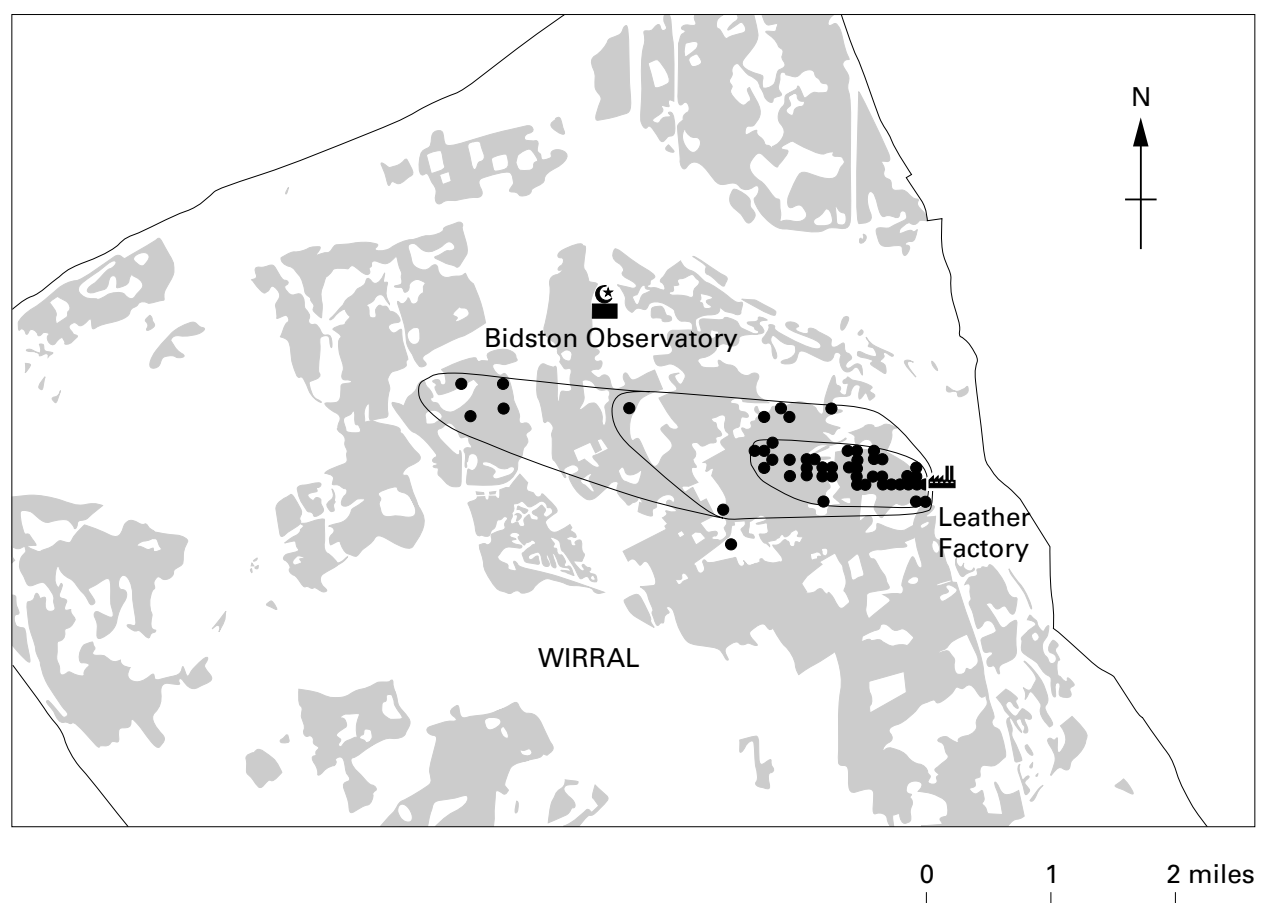

Figure 1 Map of Wirral showing location calls for assistance to environmental health department, leather factory fire, Bidston Observatory and residential areas.

It is concluded that the predominant source of asbestos deposited in the surrounding urban area was asbestos bitumen paper from the factory roof. It was estimated that the roof of the factory contained $240 \mathrm{~kg}$ of chrysotile. Much of this weight was removed while still attached to corrugated steel sheeting at the fire site, as debris cleared up by the local council clean up operation, or by the public disposing of debris themselves. Some material was denatured by the high temperature of the fire and will therefore have lost its pathogenicity (table 1). ${ }^{1617}$ Fibres would have been released during the break up of the roof during the fire and during disturbance of material in the environment. Two days after the incident it rained lightly for five hours in the morning followed by moderate to heavy rainfall later that day. In the open air respirable fibres will remain airborne until washed out by rain or snow. ${ }^{17}$ It is therefore assumed that exposure from fibres released during the fire would not have lasted more than 48 hours.

EXPOSED POPULATIONS

From occupational health records held by the fire brigade and police, 134 firemen and 19 policemen were known to have attended the incident. About 20 clean up workers were employed, and these men were issued with protective suits and dust filtering face masks.

Of 105 telephone calls from members of the public to the local environmental health department, most were to ask for help to remove fallout from the environment. Most calls were from within one mile of the fire and in a band half a mile wide, with a lesser density of calls in a two by one mile area, and a least density of calls in a four by one mile area. Populations of 16000,32000 and 48000 people were estimated to live in areas of greatest to least density of fallout (fig 1).

EVIDENCE ON LONG TERM RISKS FROM THE LITERATURE

There is good evidence that chrysotile or amosite fibres can cause ill effects after inhalation. ${ }^{9}{ }^{18}$ It takes at least 10 years of asbestos exposure for asbestosis to develop therefore this risk does not need to be considered further. ${ }^{9}$ The two cancers clearly caused by asbestos exposure are lung cancer and mesothelioma, and these are further discussed below.

CHRYSOTILE AND LUNG CANCER RISK MODEL In a study of a cohort of asbestos textile factory workers in Rochdale it was found that the greatest risk was in people who started work age 20 years, and continued to work for 35 years at an average factory chrysotile concentration of 0.25 regulated fibres per $\mathrm{ml}$. Their excess risk was six extra deaths at age 80 years for every 1000 people exposed. ${ }^{18}$ From the Rochdale cohort Doll and Peto describe a linear non-threshold model that has been used in both the UK and USA to predict risk of lung cancer from chrysotile exposure. ${ }^{18} 19$

The linear non-threshold model, which implies that any chrysotile exposure, no matter how small or brief, will result in some increase in risk, is described by the equation ${ }^{19}$;

Relative risk $=\mathrm{O} / \mathrm{E}=1+\mathrm{b} \times$ cumulative exposure [1]

$\mathrm{O}$ is the number of cases observed, $\mathrm{E}$ is the number of cases expected in the absence of chrysotile exposure, $b$ is a constant and the cumulative exposure is in fibres per ml years.

An example of the use of this model for risk estimation using industrial level exposures and 
Table 5 Estimates of relative risk for lung cancer from chrysotile exposure in this incident based on the linear non-threshold model, ${ }^{18}$ assuming exposure to stated average air concentrations of chrysotile, expressed as number of regulated fibres $>5 \mu \mathrm{m}$ and a duration of exposure of 48 hours

\begin{tabular}{lllll}
\hline $\begin{array}{l}\text { Air concentration } \\
\text { fibres/ml }\end{array}$ & $\begin{array}{l}\text { Cumulative } \\
\text { exposure } \\
\text { fibresml/ years }\end{array}$ & $\begin{array}{l}\text { Computed } \\
\text { relative risk }\end{array}$ & $\begin{array}{l}\text { Predicted exposed population } \\
\text { needed for one extra lung } \\
\text { cancer death (millions) }\end{array}$ & Exposure \\
\hline $\begin{array}{l}\text { Assuming b }= \\
0.0006 \text { (equation [1]) }\end{array}$ & & & \\
0.5 & 0.008 & 1.0000049 & 3 & I \\
0.25 & 0.004 & 1.0000025 & 6 & II \\
0.1 & 0.002 & 1.0000010 & 14 & \\
0.04 & 0.0003 & 1.0000004 & 36 & II \\
0.001 & 0.00002 & 1.00000001 & 1450 & IV \\
Assuming b $=0.01$ (equation [1]) & & & I \\
0.5 & 0.008 & 1.000082 & 0.17 & II \\
0.25 & 0.004 & 1.000041 & 0.35 & \\
0.1 & 0.002 & 1.000016 & 0.87 & III \\
0.04 & 0.0003 & 1.000007 & 2 & IV \\
0.001 & 0.00002 & 1.0000002 & 86 &
\end{tabular}

United Kingdom industrial control limit. ${ }^{33}$ Average exposure level if the United Kingdom industrial control limit is enforced. ${ }^{33}$ Upper limit of asbestos concentration indoors in a building with friable sprayed asbestos. ${ }^{25}$ Lower limit of asbestos concentration indoors in a building with friable sprayed asbestos, and a median level for residential air in a large city or a road crossing with heavy traffic. ${ }^{25} \star$ See method above under chrysotile and lung cancer risk model.

correlating that with asbestos exposure is as follows. An average air concentration of 0.1 chrysotile fibres per $\mathrm{ml}(0.25$ is average exposure level to asbestos if UK industrial control limit is enforced, table 5) equates to a concentration of 100 fibres per litre. The amount of air inspired a minute is normally about six litres $(500 \mathrm{ml}$ per breath $\times 12$ breaths per minute).$^{20}$ Therefore, at this concentration a person will inhale 600 asbestos fibres a minute, 36000 fibres an hour, 300000 fibres an eight hour shift, 100 million fibres a year, and a billion fibres in 10 years' work. Using the Doll and Peto model, ${ }^{18}$ of 200 workers inhaling a few billion pathogenic chrysotile fibres during their working life from age 20 years, one would be expected to die by age 80 of lung cancer attributable to their occupational chrysotile exposure.

As a further example, assume a worker is exposed to 0.1 chrysotile fibres per $\mathrm{ml}$ of air for 10 years, and has a cumulative exposure of 1 fibre per ml year. With a value of the constant b of 0.01 the relative risk of lung cancer death is estimated to be 1.01. If a population of 100000 people with a lifetime risk of lung cancer of $7 \%$ were exposed to this dose of chrysotile, then 7000 of this cohort would be expected to die of lung cancer, and the linear non-threshold model predicts that an extra 70 cases of lung cancer would be observed in those exposed to this dose of chrysotile.

When the Doll and Peto model ${ }^{18}$ is applied to the estimated exposed community populations in this incident $(16000,32000$ or 48000 , see above), assumed to be exposed to the UK industrial control limit for two days (see above), the long term risk of cancer is estimated to be immeasurably small (table 5). Risk estimates were made using two values for the constant $b$, of 0.01 and 0.0006 . The choice of constants is discussed later.

An example of the method for the calculation of a risk estimate in this incident (table 5) is:

(1) assume that a person inhaled air with an airborne chrysotile concentration of 0.1 fibres/ml for two days (equivalent to six working days of eight hours each), then the cumulative exposure level would be; $6 / 365 \times$ $0.1=0.0016$ fibres $/ \mathrm{ml}$ year

(2) assume $b=0.0006$

(3) It follows from equation [1] that the predicted relative risk of lung cancer;

Observed $/$ Expected $=1+0.0006 \times 0.0016=$ 1.000001 .

In Mersey Region lung cancer accounts for about $7 \%$ of all deaths, thus:

The excess risk $=0.07 \times$ relative risk -0.07

$=0.07 \times 1.000001-0.07$

$=0.00000007$

Predicted exposed population for 1 extra death $=1$ /excess risk

$=\mathrm{c} 14$ million

\section{CHRYSOTILE AND MESOTHELIOMA}

Of 3845 observed deaths in men occupationally exposed to largely chrysotile asbestos (with a small proportion of crocidolite), only 11 were from pleural mesothelioma $(0.3 \%$ of deaths $) .{ }^{18}$ Doll and Peto ${ }^{18}$ constructed a model of mesothelioma risk but it had little predictive success when applied to several cohorts of industrial workers. ${ }^{9}$ In chrysotile exposed Rochdale asbestos textile workers, the excess absolute risk of mesothelioma was $10 \%$ to $20 \%$ that of lung cancer, ${ }^{21}$ and is therefore also estimated to be immeasurably small.

AMOSITE AND LUNG CANCER

It has only been since the early 1970 s that the adverse health effects of amosite have become apparent. ${ }^{22}$ In a summary of the two studies in which industrial exposure to amosite occurred virtually alone, ${ }^{23}{ }^{24}$ Doll and Peto ${ }^{18}$ concluded that exposure to amosite for under nine months in industrial work was associated with a twofold to sixfold increased risk of lung cancer, which is incident 25 to 45 years after exposure. Seidman et $a^{22}$ studied intense industrial exposure to amosite for less than one month in 61 workers and found 3 deaths 30 years later compared with the 1.3 expected. Acheson et $a l^{23}$ found no difference in the lung cancer rates in workers exposed to "background" levels who may have had occasional exposure to air with more than 2 fibres $/ \mathrm{ml}$. These data suggest that even if the trace amounts of amosite observed in this incident were from the fire, any theoretical risk of amosite induced lung disease will be undetectable.

\section{AMOSITE AND MESOTHELIOMA}

In a cohort of amosite workers mesothelioma accounted for $2 \%$ of 857 deaths. ${ }^{18}$ Of about 700 men who were first exposed before 1960 in an amosite insulation board factory four deaths were observed from mesothelioma by $1980 .^{24}$ These men worked in areas where counts of 30 fibres $/ \mathrm{ml}$ were found when measurements began in the late 1960 s, and probably much higher levels before 1964 . No cases of mesothelioma were observed over 30 years later in men exposed industrially to amosite for less than six months. ${ }^{22}$ It is concluded that the mesothelioma risk caused by brief asbestos exposure seems to be extremely low, ${ }^{25}$ and that the risk of 
any amosite exposure in this incident is undetectably small.

PROPORTIONAL MORTALITY RATIOS (PMR)

The PMR for an occupational group is the ratio of the actual number of deaths to the expected number, multiplied by 100 . If the observed number of deaths is greater, or less, than expected, the PMR will be greater, or less than 100 . The proportional mortality ratio for metal plate workers and vehicle body builders are both above $600 .{ }^{26}$ Proportional mortality ratios for firemen, policemen, and road sweepers are all below 100 (Clegg, Health and Safety Executive, Bootle, personal communication).

\section{Discussion}

Empirical data on probable level of asbestos exposure, was synthesised with a literature review to assess what risk that exposure might imply. ${ }^{27}$ Risk was estimated to be immeasurably small. The author is not aware of a similar study of long term health risk assessment in a community exposed to asbestos in a fire.

In the model used to predict lung cancer risk from chrysotile exposure there are validity issues.

(1) there are no accurate individual exposure data

(2) how exactly asbestos fibres cause cancer is uncertain.

(3) the models that have been developed to predict the effects of asbestos exposure are from past industrial exposures when the intensity and duration of exposure greatly exceeded that probable in this incident. Consequently observed data used to construct the models do not include the low level of exposures whose effect the models are predicting. Extrapolation of predictions beyond observed data is of questionable validity. ${ }^{28}$ There is evidence that even many years employed at the lowest intensity levels of asbestos exposure have no effect, such that Browne ${ }^{9}$ argues there is a threshold for exposure. Neither the presence or absence of a threshold can be proven, and the most protective public health stance is to assume that there is no threshold for carcinogenesis. Furthermore, there is general agreement that the linear non-threshold model (see above) possibly overestimates risk from low cumulative exposure, but does not underestimate it. ${ }^{29}$ Therefore, it is concluded that the model used is the best available, and gives a broad idea of the size of any risk possible from this incident.

Limitations of these estimates also arise because of difficulty in taking into account or measuring; age at exposure; duration of exposure; fibre size; fibre type; cigarette smoking; and the amount of a person's asbestos exposure. ${ }^{18}$ There are also some assumptions in the linear non-threshold model that while plausible cannot be proven; (i) relative risk for lung cancer increases linearly during exposure at constant level and remains constant after exposure has ceased; (ii) relative risk for lung cancer is independent of both age at exposure and smoking; (iii) increase in relative risk caused by a given intensity of exposure is proportional to duration of exposure; (iv) increase in relative risk caused by a given duration of exposure is proportional to average intensity of exposure. ${ }^{18}$

There has been some debate about the most valid value for the constant, $b$ in the model [1]. In several mixed fibre cohorts and one chrysotile textile cohort a constant of around 0.01 has been found, and used to predict risk in the UK and USA. ${ }^{16}{ }^{30}$ However, Hughes ${ }^{16}$ argues that for a population exposed to non-textile chrysotile, then available data suggest a constant of 0.0006 is more appropriate. Reasons for the differences may be the more pathogenic fibre dimensions in textile manufacture ${ }^{16}$ inadequate adjustment for crocidolite exposure in Doll and Peto's (1995) model, ${ }^{15}$ and/or the use of carcinogenic and fibrogenic mineral oil sprays in the textile industry. ${ }^{9}$ Thus the constant that is more likely to be valid in this incident is 0.0006 . Even with the higher constant the risk is immeasurably small. Also the assumption that exposure reached the industrial control limit for two days is likely to greatly overestimate exposure.

In the case of estimating risk of mesothelioma from chrysotile exposure or cancer risk from amosite exposure no good quantitative models exist, and qualitative estimates of risk were required.

Several months after the event a local press report cited the local Trades Union Council ${ }^{31}$ "We are dealing with something which could be a major disaster for the people and the environment." Clearly fear of an invisible threat did frighten people during this incident. ${ }^{11}$ Carcinogenic substances like asbestos are traditionally considered to have a non-threshold effect. ${ }^{27} 32$ This implies that any chrysotile exposure, no matter how small or brief, will result in some increase in relative risk, hence the assertion that one fibre may kill. This study puts the cancer risk into perspective in that from the literature only a small minority of workers died from an excess cancer risk even when they inhaled an estimate of billions of asbestos fibres during their lifetimes. Neither the model used to calculate risk $^{29}$ nor the exposure assumptions are likely to underestimate risk. Even when the most pessimistic and inconceivable scenario is used cancer risk is estimated to be immeasurably small (table 5).

What effect did this report have? This study was shared with all interested parties who were very keen to see it. Legal and press interest in the incident seemed to peter out subsequently. No direct measure of the study on public anxiety was made. Inevitably in any real world incident there are inherent academic limitations to risk assessment that are not present in a controlled experiment. However, in this incident information about the incident and existing scientific evidence of health risks of asbestos were combined in an innovative way to provide a an assessment of long term community health risks. Informal feedback received was that this study was considered to have been a useful approach to put risk into context for interested parties and the local community.

What lessons might there be for others approaching a practical community health 
problem using a similar approach? The threat of litigation made agencies and the factory owners wary about cooperating and providing information. This delayed the study by many months. This is a difficult problem to resolve and may get more difficult in future. However, having a district incident plan that detailed a responsibility for public agencies to come together to write a joint report on health implications of such an incident would be helpful.

I am grateful for discussions with and advice from many people I bout this paper, but in particular I acknowledge the assistance of $\mathrm{Mr}$ John Hodgson, Senior Statistician at the Health and Safety Executive, Bootle, Merseyside; Dr J Hoskins, MRC Toxicology Unit, University of Leicester for advice on asbestos pollution; Mr M McDonnell, Public Analyst, City of Liverpool pollution; Mr M McDonnell, Public Analyst, City of Liverpoo or his personal communication; Professor Julian Peto, Professor of Cancer Epidemiology, Institute of Cancer Research, Sutton, Surrey for advice and comment on the methodology; and Mr B Tylee, Section Head for Mineral and Fibre Analysis at the Health and Safety Executive, Sheffield for his personal communication, Professor R Griffiths, West Midlands Regional Director of Public Health for practical public health advice on this work, Mr M Cox, Public Health Audit Assistant, North Staffordshire Health Authority, for drawing figure 1. The author takes full responsibility for the views, etc, expressed in this paper.

Funding: Wirral Health.

Conflicts of interest: none.

1 Roggli VL, Coin P. Mineralogy of asbestos. In: Roggli VL, Greenberg SD, Pratt PC. eds. Pathology of asbestosisassociated diseases. London: Little, Brown, 1992:1-18.

2 Benarde MA. History and state of the problem. In: Benarde MA. Asbestos: the hazardous fiber. Boca Raton, FL: CRC MA. Asbestos: the

3 Pooley FD. Asbestos mineralogy. In: Antman K, Aisner J, eds. Asbestos related malignancy. Orlando, FL: Harcourt eds. Asbestos related malignancy.

4 Control of Asbestos at Work Regulations. SI 1987 No.2115, Control of Asbestos at Work Regulations. SI 1987 No.2115, as amended by

5 Mossman BT, Bignon J, Corn M, et al. Asbestos: scientific developments and implications for public policy. Science 1990;247:294-301

6 Wilson R, Langer AM, Nolan RP, et al. Asbestos in New York City public school buildings-public policy: is there scientific basis? Regul Toxicol Pharmacol 1994;20:161-9.

7 Health and Safety Executive. Asbestos dust: the hidden killer Are you at risk? Essential advice for building maintenance, repair and refurbishment workers. Ind $(\mathrm{G}) 187 \mathrm{~L}$. Sudbury: Health and Safety Executive, 1995.

8 Health and Safety Executive. Asbestos alert for building maintenance, repair and refurbishment workers. Be aware of asbestos - the hidden killer. Ind $(\mathrm{G}) 188 \mathrm{P}$. Sudbury: Health and Safety Executive, 1995.

9 Browne K. Asbestos-related disorders. In: Parkes WR, ed. Browne K. Asbestos-related disorders. In: Parkes WR, ed. Occupational lung disorder.

10 Bridgman SA. Health consequences, health risks, and lessons learnt following a fire associated with asbestos-containing fallout. University of Keele, Industrial and Community Health Research Centre: University of Keele, 1996.

11 Bridgman SA. Lessons learnt from a fire associated with asbestos containing fallout. F Public Health Med 1999;21: $158-65$

12 Bridgman SA. Acute health effects of a fire associated with asbestos containing fallout. F Public Health Med 2000;22: $400-5$.

13 Health and Safety Executive. Asbestos in bulk materials: Sampling and identification by polarised light microscopy. MDHS (Methods for the Determination of Hazardous Substances) 77. Sudbury: HSE, 1994 .

14 Health and Safety Executive. Asbestos: exposure limits and measurement of airborne dust concentrations. Environmental Hygiene Series EH10. Sudbury: HSE, 1990.

15 Health and Safety Executive. Asbestos fibres in air: light microscope methods for use with the Control of Asbestos at Work Regulations. MDHS 39/3: Methods for the Determination of Hazardous Substances. Bootle: HSE, 1990.

16 Prentice J, Keech M. Alteration of asbestos with heat. Microscopy and Analysis March; 1989.

17 Hoskins JA, Brown RC. Contamination of the air with mineral fibres following the explosive destruction of buildings and fire. Drug Metab Rev 1994;26:663-73.

18 Doll R, Peto J. Asbestos: effects on health of exposure to asbestos. London: HMSO, 1985.

9 Hughes JM. Human evidence: lung cancer mortality risk from chrysotile exposure. Ann Occup Hyg 1994;38:555-60.

20 Ganong WF. Review of medical physiology. Los Altos: Lange Medical Publications, 1985:528-71.

21 Peto J, Doll R, Hermon C, Binns W, et al. Relationship of mortality to measures of environmental asbestos pollution in an asbestos textile factory. Ann Occup Hyg 1985;29:30555 .

22 Morgan WKC. Asbestos and cancer: history and public policy. Br F Indust Med 1992;49:451-6.

23 Seidman H, Selikoff IJ, Hammond EC. Short-term asbestos work exposure and long-term observation. Ann NY Acad Sci 1979;330:61-89.

24 Acheson ED, Gardner MJ, Winter PD, et al. Cancer in a actory using amosite asbestos. Int f Epidemiol 1984;13:310.

25 Bignon J. Mineral fibres in the non-occupational environment. In: Bignon J, Peto J, Saracci R, eds.. Non-occupational exposure to mineral fibres. IARC Scientific Publications no 90. Lyon: International agency for research on Cancer (WHO) Commission of the European Communities, 1989:3-29.

26 Hutchings S, Jones J, Hodgson J. Asbestos-related diseases. In: Drever F, ed. Occupational health decennial supplment: Registrar General for England and Wales: HSE/OPCS. London: Office for National Statistics, 1995.

27 Rotenberg SL. Environmental health issues. In: Cassens BJ, ed. Preventive medicine and public health. London: Williams and Wilkins, 1992

28 Knapp RG, Miller MC. Clinical epidemiology and biostatistics. London: Williams and Wilkins, 1992.

29 Weill H, Hughes JM. Asbestos as a public health risk: disease and policy. Ann Rev Public Health 1986;7:171-92.

30 Peto J, Doll R, Hermon C, et al. Relationship of mortality to measures of environmental asbestos pollution in an asbestos textile factory. Ann Occup Hyg 1985;29:305-55.

31 Anonymous. Wirral Globe. 25 January 1995.

32 Frank AL. The riddle of risk assessment in asbestos carcinogenicity. Med Law 1997;88:333-8.

33 Health and Safety Executive. Asbestos; exposure limits and measurement of airborne dust concentration. Guidance Note EH 10 , revised 1995. Sudbury: HSE, 1995. 